\title{
Sodium Lignin Sulfonate and Sodium \\ Orthophenylphenate Interaction on Browning of Pear Fruits
}

\author{
J.W. Sitton ${ }^{1}$, M.E Patterson ${ }^{1}$ \\ and G.W. Apel ${ }^{2}$
}

Additional index words. Orzan SL-50, Steri-seal D, Lignosite 458

Summary. Immersion of Anjou pears (Pyrus communis L. cv. Beurre $\mathrm{d}$ Anjou) in sodium lignin sulfonate (SLS), a flotation agent used in hydraulic handling of pears, did not cause injury leading to skin browning. Immersion of cut pear slices in SLS discolors pear fruit flesh, but the discoloration derived from SLS pigments does not intensify with time. When the fungicide sodium orthophenylphenate (SOPP) was combined with SLS, necrotic skin mottling occurred with increased immersion times and temperatures. A white precipitate in the SLS SOPP solution accompanied phytotoxicity of pear skin tissue. Acidification of alkaline SOPP solutions ( $\mathrm{pH} 11.3$ ) with $0.01 \mathrm{~N} \mathrm{HCl}$ down to $\mathrm{pH} 10$ produced mild skin necrosis. Both acid (0.01 N HC1) and alkaline $(0.01 \mathrm{~N} \mathrm{KOH})$ solutions of SOPP and SLS SOPP combinations caused browning of pear flesh. 
cific, Bellingham Wash. ) and SOPP (sodium orthophenylphenate: Steriseal D, Steri-Seal of Washington Inc., Wenatchee, Wash.) at varying concentrations, temperatures, and $\mathrm{pH}$ values on pear skin and flesh. Flotation agents are added to the flume water used to convey and reduce injury to pear fruits in packinghouses. The desired specific gravity for pear flotation is between 1.03 and 1.06 (Sugar and Spotts, 1989). Soda ash, sodium sulfate, and sodium silicate have been used as flotation agents. SLS was introduced recently into the industry as a flotation agent and fungicide (Sugar and Spotts, 1986).

SOPP and various chlorine formulations are used in dump tank water as fruit disinfectants (Baker and Heald, 1932; Wellman, 1939), and SOPP has been combined recently with SLS. This combination occasionally has caused a hypersensitive reaction characterized by skin browning and mottling (Apel, 1989; Sugar and Spotts, 1986).

Pear disk treatments. Anjou pears at various stages of maturation and ripeness (Hanson and Mellenthin, 1979) and from different sources were used in 1988 and 1989. Four 27-mmdiameter disks, 12 to $18 \mathrm{~mm}$ thick, were removed from a uniform area on an individual pear. Eight to 10 pears were selected at random for the various temperature and $\mathrm{pH}$ studies. Injury (tissue darkening) was measured with a reflectance meter (Photovolt Corporation, New York) equipped with tri-green filter (absorbance $=416$ $\mathrm{nm}$ ). Reflectance of both the skin and flesh were assayed on eight to 10 disks per treatment. Initial measurements were taken within 5 min of removal from the pear. Reflectance were measured immediately after treatment and after 20- to 30-min intervals for up to $3 \mathrm{~h}$ after removal from the test solutions.

Immediately after the initial reflectance was measured, individual pear disks were placed in $22.3-\mathrm{ml}$ vials containing $10 \mathrm{ml}$ of water, $11 \% \mathrm{SLS}$, $2200 \mathrm{mg}$ liter $^{-1} \mathrm{SOPP}$, or combinations of SLS and SOPP. Solution temperatures were maintained using cold storage rooms (10C) or a Magni Whirl (Blue M Electric Co., Blue Island, Ill.) water bath $(25 \mathrm{C}, 35 \mathrm{C})$. After immersion, the disks were strained from the solution with cheesecloth, washed in tap water for 2 to 4 see, and placed on dry paper towels for subsequent mea- surements. Reflectance were measured again at intervals of 20 to $30 \mathrm{~min}$ for up to $3 \mathrm{~h}$ after removal from the test solutions.

Concentration, temperature, and pH treatments with SLS and SOPP on pear skins and disks. The SLS concentrations were diluted with water from the 100\% commercial product to $33 \%$ and $11 \%$. Pear disks were immersed in the SLS solutions for 90 min at $25 \mathrm{C}$.

Pear disks were immersed in solutions of $11 \%$ SLS and $2200 \mathrm{mg}$ liter $^{-1}$ SOPP, alone and in combination, and in a water control for 10, 20, 30, 90, and $130 \mathrm{~min}$ at $10 \mathrm{C}, 25 \mathrm{C}$, and $35 \mathrm{C}$.

pH effects. Pear disks were immersed in 11\% SLS (pH 4.6) and 2200 $\mu \mathrm{g} \mathrm{ml} \mathrm{m}^{-1} \mathrm{SOPP}(\mathrm{pH} 11.3$ ) and in combination ( $\mathrm{pH}$ 7.0) with unbuffered $0.01 \mathrm{~N} \mathrm{HCl}$ and $0.01 \mathrm{~N} \mathrm{KOH}$ for 30 min in a $25 \mathrm{C}$ water bath. Acidic and basic solutions without SLS or SOPP were used as control treatments. The change in $\mathrm{pH}$ with addition of SLS and SOPP to the $\mathrm{HCl}$ and $\mathrm{KOH}$ solutions were measured using a Beckman 071 $\mathrm{pH}$ meter (Beckman Instruments, Irvine, Calif.) with a combination electrode.

Concentrations of SLS and pear injury. Ninety-minute immersions in $11 \%, 33 \%$, and $100 \%$ SLS solutions at $25 \mathrm{C}$ did not cause skin damage or browning (Fig. 1A). The pear flesh (Fig. 1B) stained during the initial immersion when compared to the water

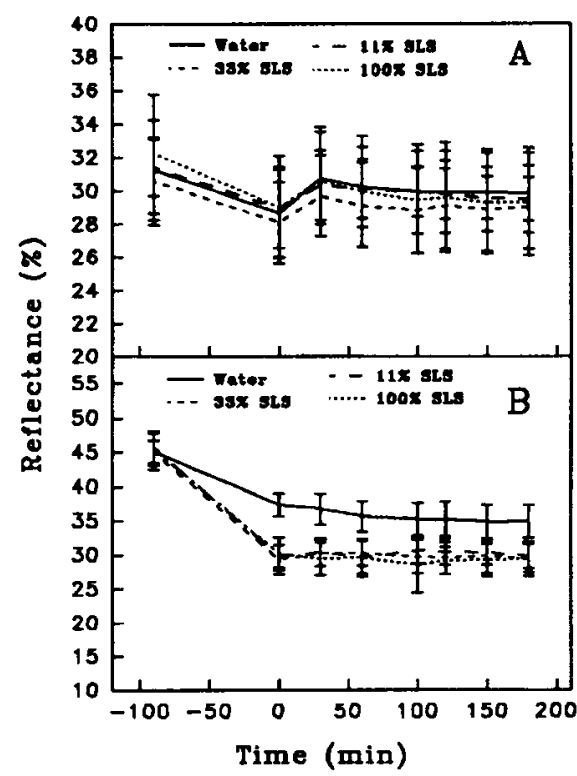

Fig. 1. Immersion in $0 \%, 11 \%, 33 \%$, and $100 \%$ sodium lignin sulfonate (SLS) at 25C for 90 min on pear skin (A) and flesh (B) browning (reflectance). Bar $=1 \mathrm{SD}$.

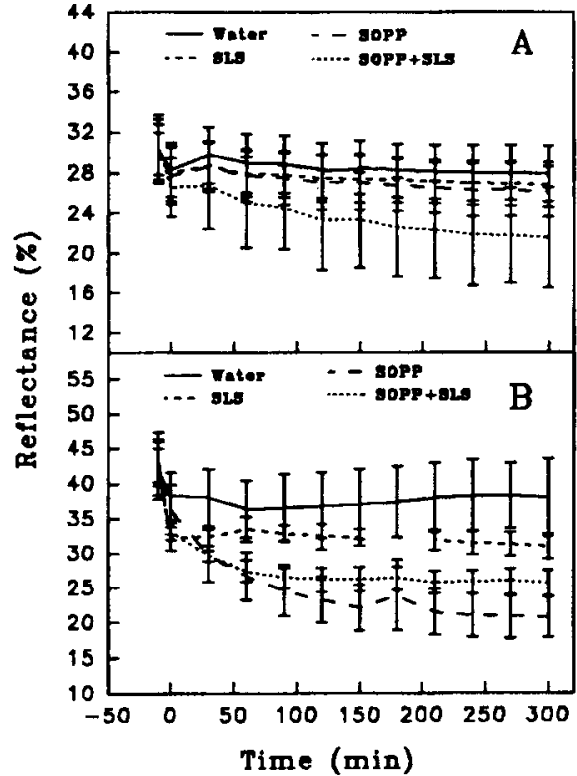

Fig. 2. Immersion in water, 11\% SLS, 2200 mg liter ${ }^{-1} S O P P$, and $11 \%$ SLS-2200 mg liter $^{-1}$ SOPP combinations at $25 \mathrm{C}$ for $20 \mathrm{~min}$ on pear skin $(A)$ and flesh $(B)$ browning (reflectance). Bar $=1 \mathrm{SD}$.

control. After removal from SLS, the pear flesh did not continue to darken with time.

SLS and SOPP temperatures on pears. SLS did not cause significant pear skin browning through the $25 \mathrm{C}$ (Figs. $1 \mathrm{~A}$ and $2 \mathrm{~A}$ ) or at 10 and $35 \mathrm{C}$ temperatures. SOPP without SLS produced a mottled, reddish-brown discoloration on pear skins when treated for $130 \mathrm{~min}$ at $10 \mathrm{C}$. When $2200 \mathrm{pg}$. $\mathrm{ml}^{-1}$ SOPP and 11\% SLS were used in combination, a milky white precipitate was produced in suspension and a reddish-brown, mottled discoloration developed around lenticels when treated for $60 \mathrm{~min}$ at $25 \mathrm{C}$ (Fig. $2 \mathrm{~A}$ ) and $130 \mathrm{~min}$ at $10 \mathrm{C}$. Generally, cool solution temperatures and/or short exposure times to SOPP, such as 10 $\min$ at $35 \mathrm{C}, 30 \mathrm{~min}$ at $25 \mathrm{C}$, and 60 min at $5 \mathrm{C}$, did not brown pear skins significantly.

The pear flesh behaved differently from pear skin tissue when exposed to SOPP and SLS. With SLS alone, SLS pigment staining occurred during the immersion phase of treatment (Figs. $1 \mathrm{~B}$ and $2 \mathrm{~B}$ ), with no additional browning developing during the observation period. SOPP alone at $2200 \mu \mathrm{g} \mathrm{ml}$ produced flesh necrosis in the following solutions: $25 \mathrm{C}$ for $60 \mathrm{~min}$ (Fig. 2B), 10C for 130 rein, and 35C for 10 min. When SLS was combined with SOPP, necrotic browning was reduced, but it was not significantly (Fig. 2B) 
different than treatment with SOPP alone.

pH and SOPP-SLS-treated pears. A white precipitate was formed in SOPP solutions acidified withO.01 $\mathrm{N} \mathrm{HCl}, \mathrm{pH}$ 2.2. SLS amended with $0.01 \mathrm{~N} \mathrm{HCl}$ had a $\mathrm{pH}$ of 4.4 , with no precipitate. Very severe, rapid browning occurred in pear skins treated with $2200 \mu \mathrm{g} \mathrm{ml} \mathrm{m}^{-1} \mathrm{SOPP}$ in $0.01 \mathrm{~N} \mathrm{HCl}$ (Fig. 3A). When the acidity became less, the SOPP toxicity was reduced. Alkaline $(0.01 \mathrm{~N} \mathrm{KOH})$ solutions (Fig. $4 \mathrm{~A}$ ), at $\mathrm{pH} 11.4$, gave a very mild skinbrowning reaction, with negligible necrosis in a $0.01 \mathrm{~N} \mathrm{KOH}$ solution (Fig. $4 \mathrm{~A})$.

Flesh responses to SOPP, SLS, and SOPP SLS combinations were different from skin reactions. The skin was mottled, while the flesh was an even, brown color. Acidification of SOPP and SOPP SLS combinations increased browning (Fig. 3B) when compared to water and SLS alone. In alkaline $(0.01 \mathrm{NKOH})$ regimes, SOPP alone at $2200 \mu \mathrm{g} \mathrm{ml}{ }^{-1}$ produced severe browning (Fig. 3B).

Sodium lignin sulfonate, when used alone, is remarkably nonphytotoxic over a wide range of concentrations, temperatures, and $\mathrm{pH}$ regimes. Moreover, SLS has beneficial flotation and disinfectant properties. After initial immersion, which results in some staining, pear flesh tissue maintains its

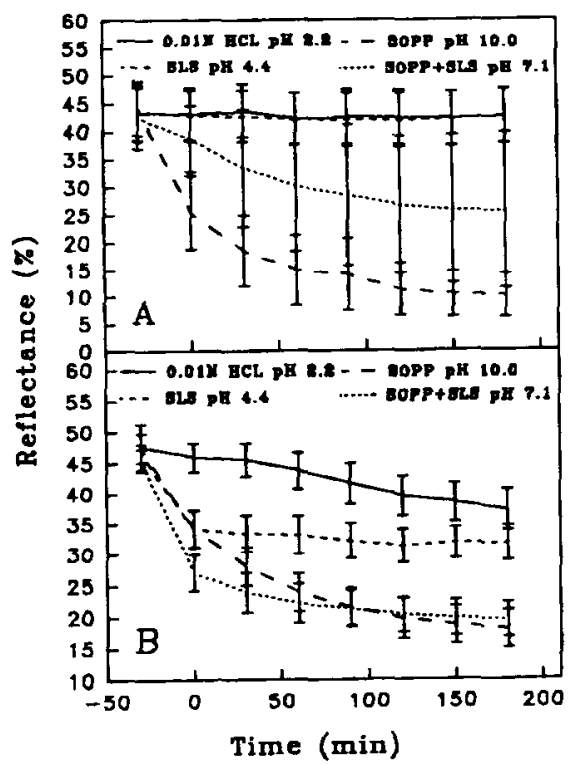

Fig. 3. Immersion in $0.01 \mathrm{~N} \mathrm{HCl,} 0.01 \mathrm{~N} \mathrm{HCl}$ $+11 \% \mathrm{SLS}, 0.01 \mathrm{~N} \mathrm{HCl}+2200 \mathrm{mg}_{\text {liter }^{-1}}$ SOPP, and $0.01 \mathrm{~N} \mathrm{HCl}+11 \%$ SLS-2200 mg liter ${ }^{-1}$ SOPP combinations at $25 C$ for 30 min on pear skin (A) and flesh (B) browning (reflectance). Bar = $1 \mathrm{SD}$.

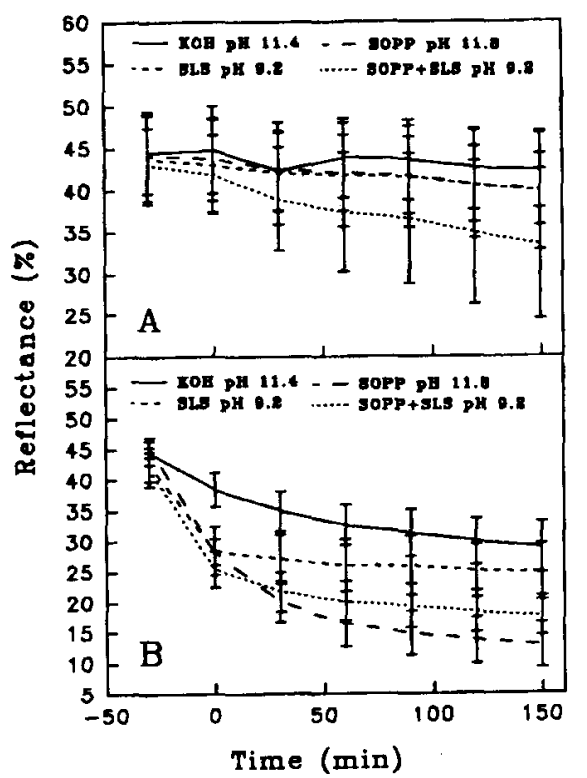

Fig. 4. Immersion in 0.01 N KOH, $0.01 \mathrm{~N}$ $\mathrm{KOH}+11 \% \mathrm{SLS} 0.01 \mathrm{~N} \mathrm{KOH}+2200$ $m g$ liter ${ }^{-1} \mathrm{SOPP}$, and $0.01 \mathrm{~N} \mathrm{KOH}+11 \%$ SLS-2200 mg liter ${ }^{-1}$ SOPP combinations at $25 \mathrm{C}$ for 30 min on pear skin (A) and flesh (B) browning (reflectance). Bar = $1 \mathrm{SD}$.

color. The addition of SLS tended to moderate the phytotoxic properties of SOPP.

SOPP is especially toxic to pear flesh; the tissue darkens and becomes soft (personal observation). The observed flesh reactions were an even brown; while skin symptoms were reddish-brown and mottled. When mixing chemicals, in particular SOPP with SLS and SOPP with $0.01 \mathrm{~N} \mathrm{HCl,} \mathrm{a}$ white precipitate was produced in the aqueous solution. This precipitate may be the result of free phenol, which was toxic to fruit (Apel, 1989). Severe skin mottling seems to have been associated with this precipitate.

High temperature and prolonged treatment of pear tissue with combinations of SLS and SOPP tended to accentuate both skin and flesh necrosis. However, the reactions were manifest even in cool (10C) solutions, when the exposure time was increased. These reactions were probably the result of enzymatic oxidative browning reactions influenced by temperature and chemical concentrations of SLS and SOPP.

The work of Sugar and Spotts (1986) has shown that SLS has fungicidal properties and our work shows that it does not detract from the appearance of the fruit when used alone. Our work elucidates the hazards of SLS and SOPP combinations, in par- ticular in acid regimens. The eventual withdrawal of SOPP from the market may not be a serious disadvantage to the pear storage industry, if SLS is able to fill the void left by the lack of SOPP disinfectant. More work is required to study the disinfectant properties of SLS at various concentrations.

In conclusion, SLS, without the addition of SOPP, was not toxic to pear skin or flesh under any of the conditions imposed. Lack of toxicity to the fruit skin was not altered by skin colors ranging from green to yellowgreen. Toxicity was not induced by immersion in $100 \%$ SLS solutions, nor was it produced by acid or alkaline solutions. Neither high nor low temperatures, nor duration of immersion, caused skin toxicity. Although the fruit flesh was stained by SLS pigments, in the absence of SOPP, the exposed flesh remained free of damage due to concentration, $\mathrm{pH}$, temperature, and immersion time.

SOPP could be damaging to both skin and flesh. Increased concentrations, temperatures, acidity , and immersion time augmented damage. When SOPP was combined with SLS, the toxicity was attenuated.

\section{Acknowledgement}

This study was funded by ITT Rayonier Inc., 18000 Pacific Highway South, Suite 900, Seattle, WA 98188.

\section{Literature Cited}

Apel, G.W. 1989. Dump tank chemicals. Washington St. Univ. Postharvest Pomol. Nwsl. 7 (2):10-12.

Baker, K.F. and F.D. Heald. 1932. Some problems concerning blue mold in relation to cleaning and packing of apples. Phytopathology 22:879-898.

Hansen, E. and W.M. Mellenthin. 1979. Commercial handling and storage practices for winter pears. Agr. Expt. Sta., Oregon State Univ., Spec. Rpt. 550.

Sugar, D. and R.A. Spotts. 1986. Effects of flotation salts on spore germination of four decay fungi and on side rot of pear. Plant Dis. 70:1110-1112.

Sugar, D. and R.A. Spotts. 1989. Flotation materials for pears. Washington State Univ. Postharvest Pomol. Nwsl. 7 (2):5-7.

Wellman, R.H. 1939. Studies on the control of blue-mold decay of apples. MS Thesis, State College of Washington, Pullman. 